\title{
The Usage of Video Tutorials, Personal Support and Written Instructions for Knowledge Acquisition and Refreshment
}

DOI: 10.12776/QIP.V22I2.1065

Jane Worlitz, Anne Stabler, Ralf Woll

Received: 01 January 2018 Accepted: 09 May $2018 \quad$ Published: 31 July 2018

\begin{abstract}
Purpose: The target of this study is to reveal which aids used are the best method for acquiring knowledge. Especially by the use of Quality management tools regarding spreadsheets and statistics software. Therefore video tutorials, personal support and written instructions, as aids, are compared with and without time pressure.
\end{abstract}

Methodology/Approach: Students of the quality management class participated in two tests in order to capture user behavior. In the first part the students $(\mathrm{n}=56)$ were asked about their user behavior regarding aids after a project that lasted several months. In the second part the students $(n=40)$ were given two aids and captured which aids they are using. The duration period and the quality of the results were also documented. At the end of both tests, the students were asked about their future favorite aids.

Findings: The first test revealed that $73 \%$ of the students used the video tutorial as an aid for their work. In future situations the students would work with written instructions, as long as there is no time pressure. If time limitation is a factor, they would rather work with video tutorials again. The second test confirmed that using video tutorials allowed for a shorter duration period. $48 \%$ were using the video tutorial while $38 \%$ used the written instruction. The suitability rating of the aids as well as the quality of the result did not differ. In future situations, the students would work again with video tutorials with or without time pressure.

Research Limitation/implication: The usage of video tutorials, personal support and written instructions for the application of Quality management tools with the use of appropriate software has been examined. The results do not show conclusions about the extent to which the aids are used for the mediation of complex issues. Follow-up studies are required for this purpose. 
Originality/Value of paper: Among these three aids with regard to time pressure, video tutorials as well as the personal support seem to be the most efficient. If time pressure was applied to the test setting, the video tutorial was preferred. In the considered setting the use of video tutorials is recommended.

Category: Research paper

Keywords: video tutorial; education; knowledge transfer; quality tools; software

\section{INTRODUCTION}

The usage of new media and technologies has changed the knowledge transfer over the past several decades. Learning platforms are often used to provide scripts, texts, and handouts, via the Internet, for all learners. Another innovation of the computer age is e-learning. Computer-based learning has evolved the increasingly popular teaching style of the video tutorial. Such learning videos can be used for self-organized learning.

In this work, the available tools that are used for the acquisition of knowledge and revitalization is investigated. The use of video tutorials as an aid is compared with the use of written instructions and the personal support of third parties.

The user behavior in regard to the aids will be tested in the utilization of Quality management (QM) software tools. The software skills among the participants are heterogeneous. For that reason, aids for the acquisition of knowledge and revitalization are necessary.

In 2004 the European Commission of Statistics published a statistic regarding the computer skills among the European population. It was noticed that $45 \%$ of the interviewees have little to no computer skills. $44 \%$ of the $16-74$ year olds and $65 \%$ of the 16-24 year olds have basic knowledge in the usage of spreadsheet software such as common arithmetic formulae (Eurostat, 2015).

Computer skills are necessary in today's professional life. In 2017, 55\% of European employees regularly used a computer. Using software is also required by the implementation of software tools in quality management (Eurostat, 2018).

The efficient knowledge transfer and the provision of suitable tools requires the learner's awareness and willingness to use these aids.

\section{LITERATURE REVIEW}

The use of video tutorials for different areas of learning at universities and schools has been analyzed in a number of studies.

Siegel, Omer and Agrawal (1997) examine the suitability of video tutorials for an introductory course of accounting, Stefanidis, et al. (2007) for medical students, DeVaney (2009) for an online statistic course, He, Swenson and Lents (2012) for a chemistry course and Truebano and Munn (2015) for molecular biology class. 
Further studies dealing with this topic can be found from authors such as Morgan, et al. (2002) Balsley, et al. (2005), Boster, et al. (2006), Coffee and Hillier (2008), Jones, Dean and Hui-Chan (2010) and van der Meij and van der Meij (2015). All studies confirm that the learning performances supported by the use of video tutorials are similar to those supported by a teacher or other teaching materials. In some cases, the groups that used video tutorials even performed better.

In a study, the suitability of video tutorials for teaching software skills in quality management has been examined. Sixty-five students in the quality management class $(n=65)$ in the age of 19 to 28 participated in this study. $62 \%$ of the participants study Business Administration, 32\% Industrial Engineering and 7\% in other technical disciplines. The students were divided into two groups (Group 1: $\mathrm{n}=31$, Group 2: $\mathrm{n}=34$ ) and separated into two rooms. Both groups received an identical task. A QM tool should be used with the help of a software. One group was supported by a tutor, the other group got a video tutorial. Before and after the experiment, both groups got a survey to gather data such as personal data, software skills, requirements of aids and the suitability of the aids. Additionally, the task from the experiment was clocked and the result was rated. The analysis was done with the help of IBM SPSS and Microsoft Excel. The following results were revealed. The type of the used aid has no influence on the suitability of the aid, rated by the students or on the experiment's result rating and neither on the needed time to solve the problem. Video tutorials are a valid alternative to the personal tutor (Worlitz, et al., 2016).

It is questionable how these aids are provided and used with reflection on praxis.

\section{RESEARCH METHODOLOGY AND RESULTS PART I}

In order to record the user behavior, two experiments with students of the quality management class were preformed.

\subsection{Database of the Survey Part I}

In the first part a study with fifty-six students was implemented. $71 \%$ of the participants study Business Administration, 23\% Industrial Engineering and 5\% other technical disciplines. $55 \%$ of the participants were male, $45 \%$ female.

\subsection{Survey Strategy Part I}

The students worked on an improvement project in cooperation with a company. It was necessary to use QM tools with the help of software. In the beginning different aids were provided to the students, such as video tutorials. After the project was finished, the students were interviewed with the use of an online survey about their usage of the aids. 


\subsection{Survey Results Part I}

In these improvement projects, $73 \%$ of the students used video tutorials. The students were asked to rank the aids for knowledge acquisition and revitalization, from most efficient to least efficient, if they would be part of an improvement project team in a company and would have to use a QM tool (see Fig. 1).

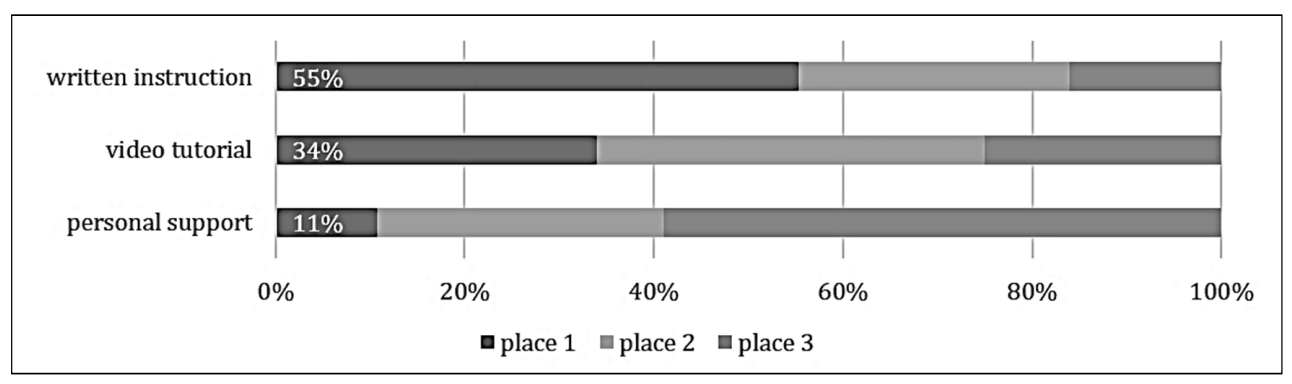

Figure 1 - Ranking of Aids

As a result it can be assumed that the students would predominantly use written instructions, rather than video tutorials and as a last resort the personal support.

The students were also asked if they would change this ranking if they would have to complete the task as quickly as possible (see Fig. 2).

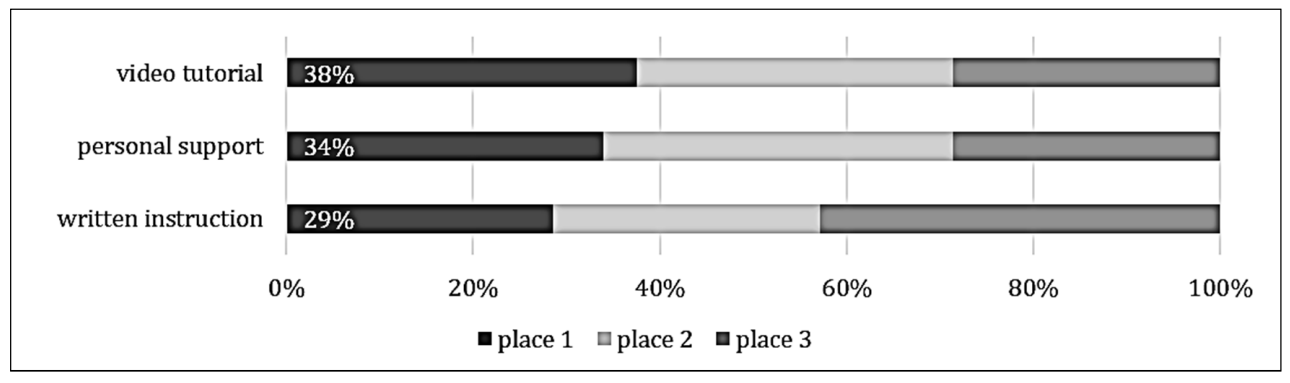

Figure 2 - Ranking of Aids, Pressed for Time

As the results reveal, written instructions drop from the first rank to the third. $38 \%$ would use video tutorials, $34 \%$ would prefer personal support.

\section{RESEARCH METHODOLOGY AND RESULTS PART II}

Based on the results of the first study, the suitability and user behavior of video tutorials was compared to written instructions.

The following three hypothesis were created.

H 1 a The type of the predominantly used aid (video tutorial or written instruction) has an influence on the rated suitability of the aid in order to solve the task. 
$H 1 \mathrm{~b}$ The type of the predominantly used aid (video tutorial or written instruction) has an influence on the results the students achieved in the task.

H $1 \mathrm{c}$ The type of the predominantly used aid (video tutorial or written instruction) has an influence on the time which was necessary to solve the task.

\subsection{Database of the Survey Part II}

Fourty students in the age from 19 to 31 from the quality management class participated in this study. 53\% of the participants study Business Administration, $40 \%$ Industrial Engineering and $7 \%$ other technical disciplines. $58 \%$ of the participants were male, $43 \%$ female.

\subsection{Survey Strategy Part II}

The task given to the students was to create a Quality Control Chart by the use of MS Excel. All data was provided via an online portal. Aids for the task were provided, such as a video tutorial a as well as written instructions, both were created by the same tutor. The students were free to choose which aid they used and asked to record the claimed time for the task. The task was provided within an MS Excel spreadsheet. The result was submitted via e-Mail.

The students were asked to fill out a questionnaire before and after the task. By using identification numbers it was possible to match the questionnaires with the submitted task. It took about ten minutes to complete the survey. The two questionnaires were designed as follows.

The first questionnaire, which was completed before the task, contained a small introductory text followed by personal data, software skills and general knowledge acquisition.

After the task, a second questionnaire was filled out by the students. The questionnaire was divided into two parts. In one part the general user behavior regarding aids was gathered. In the other part the students were asked about the suitability of the aids regarding the given task.

\subsection{Survey Results Part II-I}

The survey revealed following results regarding software skills, the acquisition of knowledge and the general user behavior regarding the aids.

With the use of a 7-Point-Likert scale from 1 "very low" to 7 "very high" the participants were asked about their software skills. The students estimated their MS Excel skills in a medium range $(\bar{x}=3.85)$. Knowledge with similar software was rated lower $(\bar{x}=2.71)$. So the students are capable to use basic functions such as formulas, diagrams and formatting. 
With the use of a 7-Point-Likert scale from 1 "rarely" to 7 "very often" the participants were asked about for which purpose they would use this aid. The students used the aids for knowledge acquisition as well as knowledge revitalization (Fig. 3).

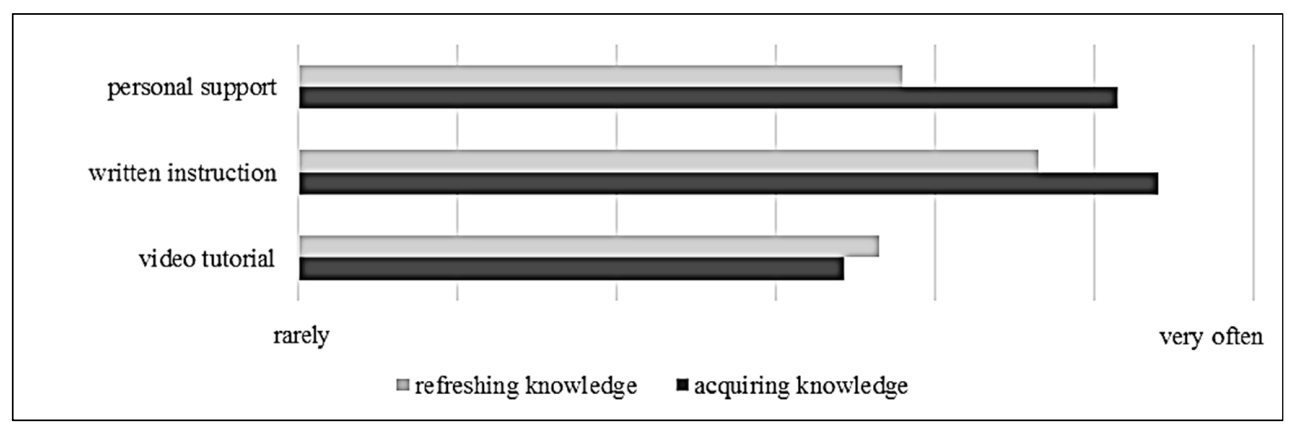

Figure 3 - Usage of Aids

The participants are using video tutorials often for personal purposes $(\bar{x}=5.18)$ as well as university purposes $(\bar{x}=5.15)$. Written instructions are used somewhat often for personal purposes $(\bar{x}=4.45)$ and often for university purposes $(\bar{x}=5.37)$. Both aids are occasionally used to improve MS Excel knowledge $\left(\bar{x}_{V T}\right.$ $=3.5 ; \bar{x}_{S I}=3.11$ ).

Written instructions are predominantly used to demand facts and video tutorials are used to gain user oriented knowledge (Fig. 4).

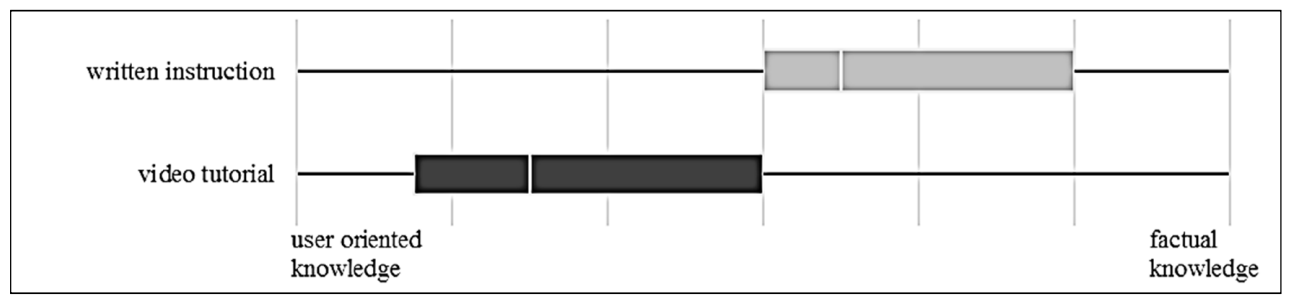

Figure 4-User Behavior Based on the Type of Knowledge

More than $50 \%$ of the participants are using video tutorials and written instruction once a week (see Fig. 5).

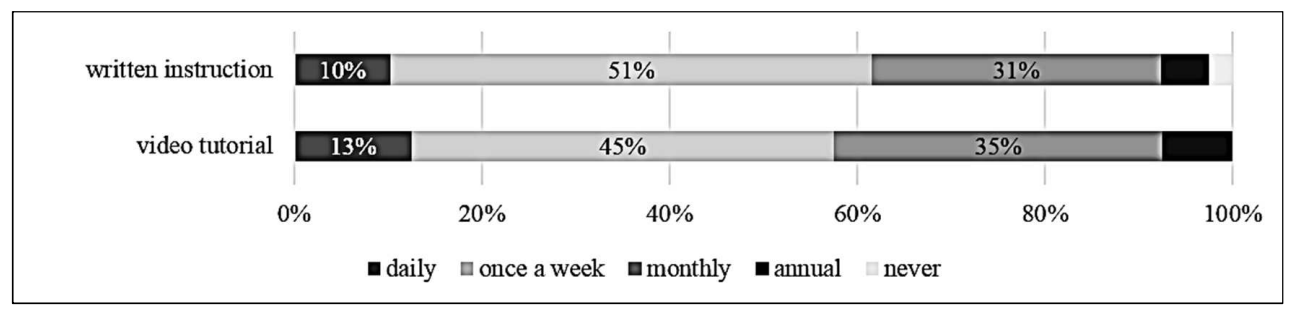

Figure 5 - Usage Frequency 
In the process of the practical task, 48\% (19 students) predominantly used the video tutorial, which means more than $60 \%$ of the overall-aid-usage. $38 \%$ (15 students) predominantly used written instructions. The others (15\%) did not use one of the two aids to more than $60 \%$. That means, no aid was used or a different aid was used or both aids were used in equal shares.

\subsection{Survey Results Part II-II}

The survey regarding the suitability of aids enables the review of the hypothesis. Thirty-four students $(n=34)$ participated in this survey, which were using predominantly one aid. Based on the students' answers the hypotheses were tested. The analysis was done with the help of IBM SPSS Statistics (see Tab. 1, Tab. 2 and Tab. 3).

Table 1 - Test Hypothesis a

How useful was the provided aid regarding the task?

\begin{tabular}{|l|l|l|l|}
\hline Null hypothesis & Test & Sig. & Decision \\
\hline $\begin{array}{l}\text { The distribution across the categories } \\
\text {,type of aid“ is identical. }\end{array}$ & $\begin{array}{l}\text { Mann-Whitney-U-Test for } \\
\text { independent sample }\end{array}$ & 0.127 & $\begin{array}{l}\text { Keep null } \\
\text { hypothesis }\end{array}$ \\
\hline
\end{tabular}

$\rightarrow H O$ a is not rejected. The type of the predominantly used aid has no influence on the rated suitability of the aid in order to solve the task.

Table 2 - Test Hypothesis $b$

\begin{tabular}{|l|l|l|l|}
\hline How good was the task done? & Test & Sig. & Decision \\
\hline Null hypothesis & $\begin{array}{l}\text { Mann-Whitney-U-Test for } \\
\text { independent sample }\end{array}$ & 0.228 & $\begin{array}{l}\text { Keep null } \\
\text { hypothesis }\end{array}$ \\
\hline $\begin{array}{l}\text { The distribution across the categories } \\
\text {,type of aid“ is identical. }\end{array}$ &
\end{tabular}

$\mathrm{HO} b$ is not rejected. The type of the predominantly used aid has no influence on the results the students achieved in the task.

Table 3 - Test Hypothesis c

\begin{tabular}{|l|l|l|l|}
\hline How long was the duration period of the task in minutes? \\
\hline Null hypothesis & Test & Sig. & Decision \\
\hline $\begin{array}{l}\text { The distribution across the categories } \\
\text {,type of aid“ is identical. }\end{array}$ & $\begin{array}{l}\text { Mann-Whitney-U-Test for } \\
\text { independent sample }\end{array}$ & 0.047 & $\begin{array}{l}\text { Reject null } \\
\text { hypothesis }\end{array}$ \\
\hline
\end{tabular}

HO c is rejected. H1 c has a significance level of 95.3\%. The type of the predominantly used aid has influence on the time which was necessary to solve the task.

Students who predominantly used the video tutorial needed in average 30 min to process the task. Students who used the written instructions needed in average 
39 min to process the task. That implies, video tutorials suit better for tasks that have to be accomplished under time pressure.

After the task, the students were asked how they would rank the used aids, if they would have to refresh their knowledge, and if they would have to work on a similar task later (see Fig. 6).

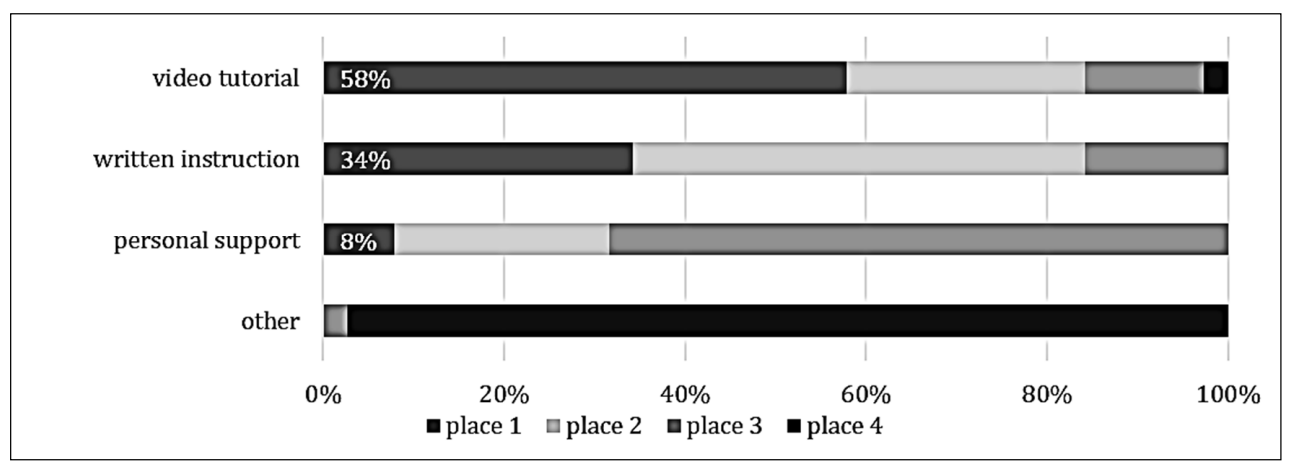

Figure 6-Ranking of Aids

The majority of students would use the video tutorial, and secondly the written instruction. The video tutorial was rated higher than in the previous ranking.

Also the students were asked how they would change the order, if they would have to work on the task under time pressure (Fig. 7).

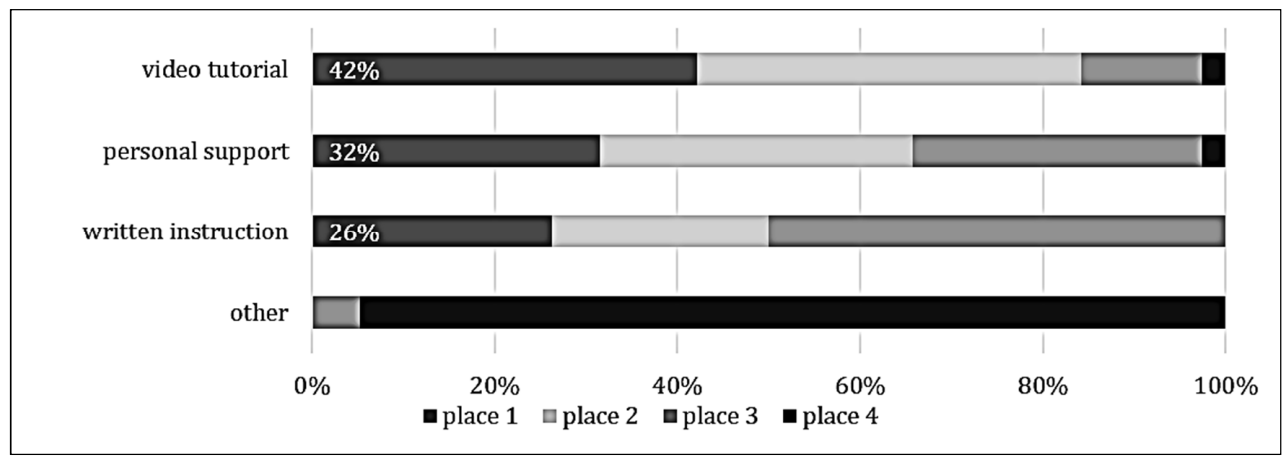

Figure 7-Ranking of Aids, Pressed for Time

As the results reveal, written instructions are now ranked third. $42 \%$ of the students would use a video tutorial first, $32 \%$ would use the personal support.

\section{DISCUSSION AND FUTURE RESEARCH DIRECTION}

The students have basic knowledge and respectively enhanced knowledge in the use of statistical and spreadsheet software. Only a few are able to work on a very advanced level. Accordingly, there is a need to close the lack of competence. 
Among the three aids, video tutorials and the personal support are the most suitable when under time pressure. In regards to time pressure, the video tutorial is preferred.

Experienced video creators would spend approximately four hours for recording a video tutorial as it was used in this experiment. The used time for the experiment's task was in average approximately half an hour. As a consequence, up to eight requests to the same topic, the personal support is the most efficient aid; assuming that personal support is available every time. Over eight requests to the same topic, video tutorials are the recommended aid.

The results are limited on the user behavior of aids used for QM tools within MS Excel. It can be assumed, that the results can be transferred on the use of QM tools within other statistical and spreadsheet software. More studies are necessary to support this thesis.

The results do not cover the user behavior of aids in complex tasks. To examine this, more studies would be necessary.

The study was implemented with students of the quality management class. Further research should focus on knowledge management in companies.

\section{CONCLUSION}

In private, as well as in university life, students regularly use video tutorials and written instructions. Video tutorials are predominantly used for gaining user oriented knowledge. For gaining factual knowledge, written instructions are used more often. Providing video tutorials for user oriented knowledge is recommended for universities, training academies and companies. Especially under time pressure, video tutorials are an efficient alternative to written instructions and personal support.

\section{REFERENCES}

Balslev, T., De Grave, W., Muijtjens, A. and Schrepbier, A., 2005. Comparison of text and video cases in a postgraduate problem based learning format. Medical Education, [e-journal] 39(11), pp.1086-1092. http://dx.doi.org/10.1111/j.13652929.2005.02314.x.

Boster, F., Meyer, G.S., Roberto, A.J., Inge, C. and Strom, R., 2006. Some Effects of Video Streaming on Educational Achievement. Communication Education, $\quad$ [e-journal] $\quad 55(1), \quad$ pp. $46-62$. http://dx.doi.org/10.1080/03634520500343392.

Coffee, J. and Hillier, S., 2008. Teaching pre-cursor clinical skills using an online audio-visual tool: an evaluation using student responses. Merlot Journal of Online Learning and Teaching, 4(4), pp.469-476. Available at: <http://jolt.merlot.org/vol4no4/coffee_1208.pdf> [Accessed July 2018]. 
DeVaney, T.A., 2009. Impact of Video Tutorials in an Online Educational Statistics Cours. Journal of Online Learning and Teaching, 5(4). Available at: $<$ http://jolt.merlot.org/vol5no4/devaney_1209.htm> [Accessed July 2018].

Eurostat, 2015. Individuals' level of computer skills. [Database by themes > General and regional statistics $>$ Degree of Urbanisation $>$ Digital economy and society $>$ Digital skills $>$ ICT users] Eurostat. [online] Available through: Eurostat - $\quad$ Data Explorer: $<$ http://appsso.eurostat.ec.europa.eu/nui/show.do?dataset=isoc_sk_cskl_i\&lang= en> [Accessed July 2015].

Eurostat, 2018. Use of computers and the internet by employees. Eurostat. [online] Available through: Eurostat - Data Explorer: $<$ http://appsso.eurostat.ec.europa.eu/nui/show.do?dataset=isoc_ci_cm_pn2\&lang $=$ en $>$ [Accessed July 2018].

He, Y., Swenson, S. and Lents, N., 2012. Online video tutorials increase learning of difficult concepts in an undergraduate analytical chemistry course. Journal of Chemical Education, [e-journal] 89(9), pp.1128-1132. http://dx.doi.org/10.1021/ed200685p.

Jones, A.Y.M., Dean, E. and Hui-Chan, C., 2010. Comparison of teaching and learning outcomes between video-linked, web-based, and classroom tutorials: An innovative international study of profession education in physical therapy. Computer \& Education, [e-journal] 54(4), pp.1193-1201. http://dx.doi.org/10.1016/j.compedu.2009.11.005.

Morgan, P., Cleave-Hogg, D., McIlory, J. and Devitt, J., 2002. Simulation technology a comparison of experiential and visual learning for undergraduate medical students. Anesthesiology, [e-journal] 96(1), pp.10-16. http://dx.doi.org/10.1097/00000542-200201000-00008.

Siegel, P., Omer, K. and Agrawal, S., 1997. Video simulation of an audit: Experimental learning theory. Accounting Education, [e-journal] 6(3), pp.217230. http://dx.doi.org/10.1080/096392897331451.

Stefanidis, D., Korndorffer, J.R., Heiniford, B.T. and Scott, D.J, 2007. Limited feedback and video tutorials optimize learning and resource utilisation during laparoscopic simulator training. Surgery, [e-journal] 142(2), pp.202-206. http://dx.doi.org/10.1016/j.surg.2007.03.009.

Truebano, M. and Munn, C., 2015. An evaluation of the use of video tutorials as supporting tools for teaching laboratory skills in biology. Practice and evidence of scholarship of teaching and learning in higher education, 10(2), pp.121-135.

van der Meij, J. and van der Meij, H., 2015. A test of the design of a video tutorial for software training. Journal of Computer Assisted Learning, [e-journal] 31(2), pp.116-132. http://dx.doi.org/10.1111/jcal.12082. 
Worlitz, J., Stabler, A., Peplowsky, S. and Woll, R., 2016. Video Tutorials: An Appropriate Way of Teaching Quality Management Tools Applied with Software. Quality Innovation Prosperity, [e-journal] 20(2), pp.169-184. http://dx.doi.org/10.12776/QIP.V20I2.754.

\section{ABOUT AUTHORS}

Jane Worlitz, M.Sc. - Research associate, e-mail: jane.worlitz@b-tu.de.

Anne Stabler, M.A. - Research assistant, e-mail: anne.stabler@b-tu.de.

Prof. Dr.-Ing. Ralf Woll - Chairholder, Chair of Quality Management, Brandenburg University of Technology Siemens-Halske Ring 14, 03046 Cottbus, Germany. The Chair of Quality Management investigates industrial tasks from the perspective of engineers regarding quality, costs as well as time and we optimise processes using tools of quality-, project- and risk management, e-mail: woll@b-tu.de.

(C) 2018 by the authors. Submitted for possible open access publication under the terms and conditions of the Creative Commons Attribution (CC-BY) license (http://creativecommons.org/licenses/by/4.0/). 